\title{
How appropriate are cerebrospinal fluid polymerase chain reaction requests for suspected central nervous system infections?
}

\author{
Yaasir Mamoojee and David Chadwick
}

\begin{abstract}
Cerebrospinal fluid (CSF) polymerase chain reaction (PCR) assays have become the main diagnostic tests for central nervous system viral infections in recent years. Previous studies have suggested algorithms based on CSF leukocyte count and total protein levels to determine when CSF PCR assays are indicated. Based on these criteria, 1,469 CSF PCR tests requested over a two-year period were reviewed. A proportion of positive PCR results were found in children with normal CSF, unlike in adults where such occurrences were extremely rare. The results suggest that applying a strategy of screening CSF specimens using leukocyte count, glucose and protein, at least in adults, may have avoided more than half of CSF PCR requests with little detriment to patient care and considerable cost savings. Larger prospective studies are needed to determine whether algorithms using standard CSF parameters and clinical information can optimise the use of CSF PCR assays in clinical practice.
\end{abstract}

KEY WORDS: central nervous system, cerebrospinal fluid, meningitis, polymerase chain reaction, viral infection

\section{Introduction}

Cerebrospinal fluid polymerase chain reaction (CSF PCR) assays have become widely available to clinicians throughout the $\mathrm{UK}$ in recent years, and are used to diagnose central nervous system (CNS) infections. Indeed CSF PCR assays to detect herpes simplex virus (HSV) encephalitis and John Cunningham (JC) virus in progressive multifocal leucoencephalopathy have become standard diagnostic assays after validation using brain biopsies as gold standards. ${ }^{1,2}$ Although CSF PCRs for other CNS viral infections have not been as rigorously validated, the diagnosis of a definite CNS infection is 88 times more likely with a positive CSF PCR result than with a negative result. ${ }^{3}$ To date, CSF PCR has become the main diagnostic method for these viral infections including enteroviruses, which is by far the most common cause of viral meningitis. ${ }^{3,4}$ Early diagnosis of CNS infections through PCR assays can improve clinical outcomes through providing earlier and specific antimicrobial

Yaasir Mamoojee, foundation trainee; David Chadwick, infectious diseases consultant

Department of Infection and Travel Medicine, James Cook University Hospital, Middlesbrough chemotherapy, and exclusion of CNS infections through rapid CSF PCR assays can reduce length of hospital stays and duration of unnecessary antimicrobial chemotherapy. ${ }^{5}$

While technically simpler than most other tests used to detect CNS infections, CSF PCR assays are relatively expensive, especially when multiple assays are requested and, to date, there are no national guidelines available advising when to request them. In practice, physicians typically order CSF PCR assays for HSV, enterovirus and varicella zoster virus (VZV) when initial CSF results are abnormal, however after initial stains and cultures are negative, or when there are other clinical features to suggest such infections. In immunocompromised patients, there is often a lower threshold for ordering CSF PCR tests, frequently including cytomegalovirus (CMV) human herpesvirus 6 (HHV6), Epstein-Barr virus (EBV) or JC virus, even when CSF protein, glucose and microscopy is normal. Other PCR assays sometimes requested in patients with aseptic meningitis include assays specific for Neisseria meningitides, Mycobacterium tuberculosis and Listeria monocytogenes.

As healthcare expenditure comes under increasing scrutiny, there is considerable pressure to deliver cost-effective as well as high-quality diagnostic services. ${ }^{6}$ To optimise effective use of CSF PCR assays, previous studies have suggested algorithms based on CSF leucocyte count and total protein levels to determine when CSF PCR assays are indicated, ${ }^{7,9}$ both of which are predictive of CNS infections. ${ }^{3,8,9}$ In order to evaluate the appropriateness of CSF PCR requests at the James Cook University Hospital on the basis of criteria recommended in one of these studies, ${ }^{7}$ a retrospective audit of all CSF PCR tests requested over a two-year period was conducted.

\section{Methods}

All CSF PCR tests requested during 2008 and 2009 were retrieved from the microbiology electronic records and the CSF microscopy, biochemistry, culture and PCR results for each patient were extracted from the hospital's electronic pathology reporting system. All CSF specimens underwent multiplex PCR assays at Micropathology Limited, University of Warwick Science Park. A CSF specimen was defined as abnormal if any of the following was present: white blood cell count (WCC) $>5$ cells $/ \mathrm{mm}^{3}$ (if red blood cells were present in the CSF sample a correction was made, and for infants less than two weeks old a WCC $>20$ cells $/ \mathrm{mm}^{3}$ was considered abnormal (10)); protein level $>0.5 \mathrm{~g} / \mathrm{l}$; CSF glucose $<2.2$ or CSF:serum glucose ratio 
Table 1. Classification of central nervous system (CNS) viral infections using clinical and laboratory criteria. Adapted from reference 3 .

Likely CNS viral infection (I and/or ii):

i. Raised CSF WCC (defined by age group) accompanied by one or more of the following: meningism, headache, or fever $\geqslant 37.5^{\circ} \mathrm{C}$ ) (with no other explanation).

ii. Altered level of consciousness or focal neurological signs accompanied by fever $\left(\geqslant 37.5^{\circ} \mathrm{C}\right)$ or headache (with no other explanation).

\section{Possible CNS viral infection:}

Attending physician's final diagnosis of a viral CNS infection with any combination of signs or symptoms.

Unlikely CNS viral infection (one of the following):

i. Another definite diagnosis (for example, multiple sclerosis or bacterial meningitis).

ii. Non-specific diagnosis (for example, febrile convulsion where clinical or laboratory features were not consistent with the above categories).

iii. No definite diagnosis (for example, fever of unknown cause where the clinical or laboratory features were not consistent with the above categories).

CSF $=$ cerebral spinal fluid; WCC $=$ white cell count.

$<0.4$. CSF PCR requests were compared between the following hospital departments: acute medicine, paediatrics and neurology. For patients in acute medicine, clinical data were extracted from medical records to classify the likelihood of CNS infection, based on criteria previously employed, ${ }^{3}$ illustrated in Table 1. Any indication for CSF PCRs to be requested simultaneously with initial CSF tests (biochemistry and microscopy) was established, for example in immunocompromised patients or where evidence of herpetic rashes or shingles, and the final diagnosis(es) was noted. The audit was registered with the hospital's audit department.
Table 2. Polymerase chain reaction (PCR) tests and positive yield.

\begin{tabular}{|c|c|c|c|}
\hline Organism & $\begin{array}{c}\text { Number of } \\
\text { of PCR } \\
\text { requests }\end{array}$ & $\begin{array}{l}\text { Number } \\
\text { of positive } \\
\text { results }\end{array}$ & $\begin{array}{l}\text { Percentage } \\
\text { of positive } \\
\text { PCR results }\end{array}$ \\
\hline Herpes viruses & 824 & 13 & 1.58 \\
\hline HSV1 & 3 & 1 & 33.3 \\
\hline HSV2 & 3 & 1 & 33.3 \\
\hline HSV (untyped) & 355 & 2 & 0.56 \\
\hline VZV & 302 & 5 & 1.66 \\
\hline CMV & 29 & 0 & 0 \\
\hline EBV & 34 & 0 & 0 \\
\hline HHV6 & 98 & 4 & 4.08 \\
\hline Enterovirus & 314 & 16 & 5.10 \\
\hline Listeria monocytogenes & 38 & 1 & 2.63 \\
\hline Neisseria Meningitidis & 80 & 5 & 6.25 \\
\hline Mycobacterium tuberculosis & 10 & 0 & 0 \\
\hline Borrelia sp. & 12 & 0 & 0 \\
\hline Others & 191 & $7^{*}$ & 3.66 \\
\hline
\end{tabular}

\section{Results}

\section{CSF PCR requests}

A total of 1,469 separate CSF PCR tests were requested during 2008 and 2009 for 379 patients. Most patients (39\%) had three different PCR tests. Eight-four patients (22\%) had more than four different CSF PCR tests, ranging from five CSF PCR tests being requested for 36 patients to a maximum 24 CSF PCR tests on a single patient.

Table 3. Comparison of cerebral spinal fluid polymerase chain reaction (CSF PCR) tests requested between the paediatrics, neurology and acute medicine.

\begin{tabular}{|c|c|c|c|c|}
\hline & Paediatrics & Neurology & Acute medicine & Total \\
\hline Number of patients & 169 & 80 & 98 & 347 \\
\hline Number of males & 96 & 43 & 56 & 195 \\
\hline (\% out of total number of patients) & $(56.8)$ & $(53.7)$ & $(57.1)$ & $(56.2)$ \\
\hline Total number of PCR tests requested & 650 & 311 & 274 & 1235 \\
\hline Average number of PCR tests per patient & 4 & 4 & 3 & 4 \\
\hline $\begin{array}{l}\text { Number of positive PCR results } \\
\text { (\% out of total number of PCR tests requested) }\end{array}$ & $\begin{array}{c}22 \\
(3.38)\end{array}$ & $\begin{array}{c}2 \\
(0.64)\end{array}$ & $\begin{array}{c}12 \\
(4.38)\end{array}$ & $\begin{array}{c}36 \\
(2.91)\end{array}$ \\
\hline $\begin{array}{l}\text { Number of patients with normal CSF } \\
\text { (\% out of total number of patients) }\end{array}$ & $\begin{array}{c}78 \\
(46.1)\end{array}$ & $\begin{array}{c}24 \\
(30)\end{array}$ & $\begin{array}{c}45 \\
(45.9)\end{array}$ & $\begin{array}{c}147 \\
(42.4)\end{array}$ \\
\hline $\begin{array}{l}\text { Number of separate PCR tests requested on normal CSF } \\
\text { (\% out of total PCR tests requested) }\end{array}$ & $\begin{array}{c}276 \\
(42.5)\end{array}$ & $\begin{array}{c}80 \\
(25.7)\end{array}$ & $\begin{array}{c}114 \\
(52.6)\end{array}$ & $\begin{array}{c}500 \\
(40.5)\end{array}$ \\
\hline $\begin{array}{l}\text { Number of positive PCR results on normal CSF } \\
\text { (\% out of total positive PCR results) }\end{array}$ & $\begin{array}{c}11 \\
(50)\end{array}$ & $\begin{array}{c}0 \\
(0)\end{array}$ & $\begin{array}{c}1 \\
(8.33)\end{array}$ & $\begin{array}{c}12 \\
(33)\end{array}$ \\
\hline
\end{tabular}


Table 2 shows the different PCR tests that were requested. Most PCR tests were requested for herpes viruses (56\%). The positive yield from all the requests was relatively low, ranging from $0.6 \%$ for HSV to $6.3 \%$ for $N$. meningitidis. Out of the five positive $N$. meningitidis PCR, one was positive on both CSF microscopy and culture, two had positive CSF cultures, one had a positive blood culture and one had abnormal CSF biochemistry only. Among the herpes viruses, only two out of 355 requests for HSV were positive while HHV6 had a relatively high positivity rate $(4.1 \%)$. In children there were 14 enterovirus, three N. meningitidis, four HHV6 and one Rotavirus positive PCR tests, while adult patients accounted for all the VZV, HSV and $L$. monocytogenes positive results.

\section{Department comparison for CSF PCR requests}

Table 3 compares the CSF PCR tests requested between these three different departments. The percentage of male patients was comparable between the three different departments, with an average of $56 \%$ of males. The mean age of patients was two, 51 and 47 years for paediatrics, neurology and acute medicine, respectively.

Paediatrics had the largest number of CSF PCR requests, accounting for almost half of the total requests. On average, four CSF PCR tests were requested per patient. However, in the adult population (neurology and acute medicine) more tests were requested from neurology (mean four tests per patient) than from acute medicine (mean three tests per patient). Interestingly the positive PCR rate in neurology was lower than that in acute medicine patients $(0.64 \%$ compared to $4.38 \%)$.

Across the three different departments almost half of the total PCR tests requested were on patients with normal CSF specimens, with a quarter of its PCR requests on normal CSF specimens in neurology and more than half of PCR requests on normal CSF specimens in acute medicine. Surprisingly, out of 36 positive PCR tests 12 were from patients with normal CSF specimens. Of these 12 specimens, 11 were from children (seven enterovirus, two HHV6, one rotavirus and one $N$. meningitidis) and one from an adult (enterovirus) in acute medicine.

\section{CSF PCR requests in acute medicine}

Over the two-year period 274 PCR tests were requested from the acute medicine department on 98 patients. Forty-five patients (46\%) had normal CSF parameters on biochemistry and microscopy. Thirty-one (out of 45) and 35 (out of 53) patient records could be retrieved for patients with normal and abnormal CSF specimens respectively. For patients with normal CSF specimens, none had a valid indication for viral CSF PCR tests to be requested simultaneously with initial CSF tests using the study criteria. Nevertheless, PCR tests were requested simultaneously with initial CSF tests in 14 out of 31 instances. For all of the 31 patients, a final diagnosis of CNS infection was 'unlikely' based on Table 1 criteria.

\begin{tabular}{|c|c|c|}
\hline & $\begin{array}{l}\text { Normal CSF } \\
\text { specimens }\end{array}$ & $\begin{array}{l}\text { Abnormal CSF } \\
\text { specimens }\end{array}$ \\
\hline Total, $\mathrm{n}$ & 31 & 35 \\
\hline \multicolumn{3}{|l|}{ Central nervous system } \\
\hline Viral infection & & 7 \\
\hline Bacterial infection & & 8 \\
\hline Migraine & 1 & \\
\hline Tension headache & 1 & 1 \\
\hline Epilepsy & & 1 \\
\hline Stroke & 1 & 1 \\
\hline \multicolumn{3}{|l|}{ Space-occupying lesion } \\
\hline $\begin{array}{l}\text { Focal or systemic infection) } \\
\text { (excluding CNS infections }\end{array}$ & 8 & 5 \\
\hline Overdose (drugs or alcohol) & 3 & 2 \\
\hline Multiple causes & $3^{*}$ & $2^{\S}$ \\
\hline No cause & 9 & 4 \\
\hline Other & $3^{\pi}$ & $4 ?$ \\
\hline \multicolumn{3}{|c|}{ 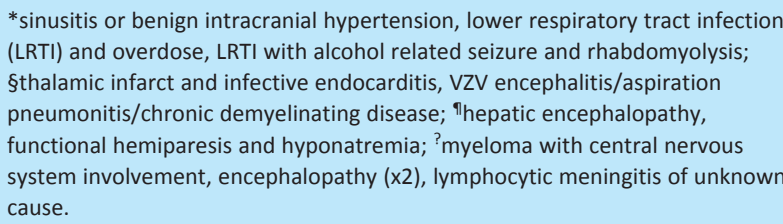 } \\
\hline
\end{tabular}

Out of the 35 patients with abnormal CSF specimens, five had valid indications for requesting viral CSF PCR tests simultaneously with CSF biochemistry and microscopy, based on clinical history and examination. However, documented evidence of CSF PCR tests being requested simultaneously with initial CSF tests were found in six cases. For 14 of these patients a final diagnosis of CNS infection was deemed 'unlikely', 20 deemed 'likely' and one 'possible'.

Table 4 compares the final diagnoses for patients in acute medicine. In a proportion of patients with normal CSF the final diagnosis was either infective in nature (non-CNS) or no cause was found. As expected, a handful of patients with abnormal CSF had a CNS infection.

\section{Discussion}

This audit has shown that a large number of CSF PCR requests are sent from this hospital each year, with a significant number of requests being sent simultaneously with initial CSF tests, and the vast majority of CSF PCR requests yielding negative results. Among the viral PCR assays the maximum positive yield (5.2\%) was obtained for enteroviral PCR tests, while less than $2 \%$ of tests for different herpesviruses were positive. This is not dissimilar to rates of positive tests found by Davies et al in a similar study. ${ }^{11}$ 
There remains some controversy as to whether a normal initial CSF result should preclude further testing by PCR, ${ }^{7,11}$ and an argument has been made for only testing patients with a possible or likely CNS infection clinically where CSF samples are normal. ${ }^{7}$ On the other hand, given that PCR assays may be negative (and CSF protein/glucose/white blood cells normal) in patients with confirmed CNS infections when CSF is obtained shortly after the onset of symptoms, other authors suggest a more cautious approach to interpreting negative PCR results. ${ }^{11,12}$ Nonetheless, the frequency with which CSF PCR requests were made prior to the results of the initial CSF test being available, particularly in adult patients unlikely to have CNS infections on clinical grounds, and the very low rate of positive results in this group suggest that many of these requests were inappropriate. Furthermore, these results show that requests for $N$. meningitidis were largely inappropriate as positive results were often available from CSF or blood cultures.

The paediatrics department at the study hospital had the largest load of CSF PCR requests in the audit. Although half of these requests were on normal CSF specimens, it was surprising that half of the positive PCR results (mostly enterovirus) were in normal CSF specimens. There is, therefore, no basis for recommending that a normal CSF should preclude testing for enteroviral PCRs in this patient group, unlike the adult group where positive viral CSF PCR results were extremely rare in patients with normal CSF. On the neurology wards, although PCR requests were less likely to be made on normal CSF, more individual PCR tests were requested and less than $1 \%$ of tests were positive.

These results suggest that applying a strategy of screening CSF specimens using leukocyte count, glucose and protein, at least in adults, may have avoided more than half of CSF PCR requests with little detriment to patient care and considerable cost savings. Larger prospective studies are needed to determine whether algorithms using standard CSF parameters and clinical information can optimise the use of CSF PCR assays in clinical practice. If such algorithms can demonstrate high negative predictive values for CNS infections it may be possible to implement standard operating procedures in microbiology departments to determine when and which CSF PCR assays should be performed.

\section{Acknowledgements}

The authors would like to thank Andrew Wyllie and Karl Hubbert in the microbiology lab at the James Cook University Hospital for assis- tance with data retrieval, Hanaa Rajabally and John Williams for their help with databases management and the clinical audit department for assistance in obtaining patient notes.

\section{References}

1 Weber T, Turner RW, Frye S et al. Specific diagnosis of progressive multifocal leucoencephalopathy by polymerase chain reaction. J Infect Dis 1994;169:1138-41.

2 Lakeman FD, Whitley RJ. Diagnosis of herpes simplex encephalitis: application of polymerase chain reaction to cerebrospinal fluid from brain biopsied patients and correlation with disease. National Institute of Allergy and Infectious Diseases Collaborative Antiviral Study Group. J Infect Dis 1995;171:857-63.

3 Jeffery KJ, Read SJ, Peto TE et al. Diagnosis of viral infections of the central nervous system: clinical interpretation of PCR results. Lancet 1997;349:313-7.

4 Vuorinen T, Vainionpaa R, Hyypia T. Five years' experience of reversetranscriptase polymerase chain reaction in daily diagnosis of enterovirus and rhinovirus infections. Clin Infect Dis 2003;37:452-5.

5 Chadwick DR, Lever AML. Presentation and impact of new diagnostic modalities in the management of meningitis in adults at a teaching hospital: a five year review. QJM 2002;95:663-70.

6 Russell LB, Gold MR, Siegal JE, Daniels N, Weinstein MC. The role of cost-effectiveness analysis in health and medicine. JAMA 1996;276:1172-7.

7 Tang YW, Hibbs JR, Tau KR et al. Effective use of polymerase chain reaction for diagnosis of central nervous system infections. Clin Infect Dis 1999;29:803-6.

8 Hayward RA, Shapiro MF, Oye RK. Laboratory testing on cerebrospinal fluid: a reappraisal. Lancet 1987;1:1-4.

9 Lindquist L, Linne T, Hanson LO, Kalin M, Axelsson G. Value of cerebrospinal fluid analysis in the differential diagnosis of meningitis: a study in 710 patients with suspected central nervous system infection. Euro J Clin Microbiol Infect Dis 1988;7:374-80.

10 Kestenbaum LA, Ebberson J, Zorc JJ, Hodinka RL, Shah SS. Defining cerebrospinal fluid white blood cell count reference values in neonates and young infants. Paediatrics 2010;125:257-64.

11 Davies NW, Brown LJ, Gonde J et al. Factors influencing PCR detection of viruses in cerebrospinal fluid of patients with suspected CNS infections. J Neurosurg Psychiatr 2005;76:82-87.

12 Minjolle S, Arvieux C, Gautier AL et al. Detection of herpesvirus genomes by polymerase chain reaction in cerebrospinal fluid and clinical findings. J Clin Virolog 2002;25(suppl 1):S59-70.

Address for correspondence: Dr D Chadwick, Department of Infection and Travel Medicine, James Cook University Hospital, Marton Road, Middlesbrough TS4 3BW.

Email: davidr.chadwick@stees.nhs.uk 